European

Thyroid Journal
Eur Thyroid J 2013;2:68

DOI: $10.1159 / 000348249$
Received: November 19, 2012

Accepted: December 10, 2012

Published online: February 16, 2013

\title{
Sporadic Cretinism: A Dangerous Misnomer
}

\author{
Gabriella Morreale de Escobar
}

CSIC/Fac. Med. UAM, Madrid, Spain

Dear Sir,

The word 'cretin' was initially used for mentally retarded, deaf-mute and usually goitrous individuals born and living in areas of very severe iodine deficiency [1]. It is believed to have originated from 'Pauvre Chrétienne' (a poor Christian), unable to distinguish between good and evil. These cretins were usually represented bearing a staff indicating their idiocy.

Unfortunately, the same word was introduced into the Western literature and medical practice for infants with untreated congenital hypothyroidism. Although some authors distinguish between 'endemic' cretinism and the 'sporadic' cretinism of the untreated congenitally hypothyroid child, the use of the same word has inadver- tently lead to the widely-held, and quite erroneous, opinion that the clinical presentation and neurological damage would be the same and, having the same etiology, could be prevented in the same manner.

But this is not so. True cretinism can only be avoided by an adequate iodine intake through gestation. This simply requires substituting all household salt, and that available to domestic animals, with iodized salt, containing $1.34 \mu \mathrm{g} \mathrm{KI} / \mathrm{kg}$ salt.

The misnamed 'sporadic' cretins, on the other hand, identified by neonatal screening programs, require prompt postnatal treatment with thyroid hormones to prevent their mental retardation.

\section{Disclosure Statement}

The author has no financial or other conflict of interest in relation to the content of the article.

\section{References}

1 Maberly GF, Haxton DP, van der Haar F: Iodine deficiency is, after severe malnutrition, the most frequent cause, worldwide, of mental retardation: consequences and progress towards elimination. Food Nutr Bull 2003; 24(suppl):S91-S98.

\section{KARGER}

E-Mail karger@karger.com www.karger.com/etj
Dr. Gabriella Morreale de Escobar CSIC/Fac. Med. UAM Arturo Duperier 4 ES-28029 Madrid (Spain)

E-Mail gmorreale@iib.uam.es 